\title{
A CÁTEDRA UNESCO DE DIREITO À EDUCAÇÃO DA FACULDADE DE DIREITO: DEMOCRACIA, CIDADANIA E DIREITO À EDUCAÇÃO
}

\author{
THE UNESCO CHAIR ON THE RIGHT TO EDUCATION IN THE LAW SCHOOL: DEMOCRACY,
}

CITIZENSHIP AND THE RIGHT TO EDUCATION

Nina Beatriz Stocco Ranieri*

Resumo:

Regimes democráticos se consolidam na medida de sua aceitação pela maioria, o que supõe conhecimento e confiança nas instituições políticas e jurídicas. A educação de qualidade é relevante para a governança democrática e para a formação da cidadania, posto propiciar o acesso a ferramentas cognitivas necessárias para a participação política relevante. As interações entre a democracia, o direito à educação e as políticas públicas de educação são analisadas pela Cátedra UNESCO no projeto de pesquisa "Brasil 25 anos de democracia" sob o ângulo da função promocional do Direito à Educação da FD, em parceria com o Núcleo de Políticas Públicas da USP, com. O foco da pesquisa é a atividade do Supremo Tribunal Federal (STF), a do Superior Tribunal de Justiça (STJ) e a do Congresso Nacional, no período compreendido entre os anos 2000 e 2010.

Palavras-chave: Democracia. UNESCO. Faculdade de Direito da Universidade de São Paulo.

\begin{abstract}
:
Democratic regimes strengthen in the extent of their acceptance by the majority, which means knowledge and confidence in the political and legal institutions. Quality education is relevant to democratic governance and citizenship formation, since providing access to cognitive tools necessary for political relevance. The interactions between democracy, the right to education and public education policies were analyzed by the UNESCO Chair on the Right to Education at the University of São Paulo Law School in the research project "Brazil, 25 years of democracy" in partnership with the USP Public Policy Center. The research focus is the activity of the Supreme Court (STF), the Superior Court of Justice (STJ) and the National Congress, in the period between 2000 and 2010.
\end{abstract}

Keywords: Democracy. UNESCO. University of Sao Paulo Law School.

Introdução

Em 2008 foi criada na Faculdade de Direito da Universidade de São Paulo a primeira Cátedra UNESCO de Direito à Educação do país, da qual participam docentes e

\footnotetext{
* Professora Associada do Departamento de Direito do Estado da Faculdade de Direito da Universidade de São Paulo. Assistente Especial do Governador do Estado de São Paulo 
alunos de graduação e pós-graduação, com o objetivo de promover estudos e pesquisas na área do direito à educação no sistema jurídico brasileiro e no direito internacional.

A Cátedra iniciou seus trabalhos na FD com o oferecimento de disciplinas de pós-graduação no âmbito do Mestrado em Direitos Humanos da FDUSP. No conjunto, são cinco dissertações de mestrado e três doutorados já defendidos por pesquisadores da Cátedra, na FD, até o início de 2013. Além das atividades de pós-graduação, a Cátedra realiza sistematização e análise de legislação e jurisprudência no campo da educação, produz doutrina, organiza seminários e debates regionais. Em cinco anos de existência, a Cátedra elaborou duas obras de referencia (Temas Relevantes do Direito à Educação e O Direito à Educação: igualdade e discriminação no ensino, ambas editadas pela EDUSP), colabora regularmente com a Revista de Direito Educacional, da Editora Revista dos Tribunais, São Paulo, para publicação de artigos científicos, transcrições de seminários, manifestações em mesas de debates e palestras organizadas pela Cátedra ou dos quais esta participe. As atividades da Cátedra expressam a crença, defendida pelos fundadores da UNESCO, a instituição da Organização das Nações Unidas para a Educação, Ciência e Cultura, de se garantirem oportunidades iguais de educação para todos.

A UNESCO criou seu Programa de Cátedras em 1992, com o objetivo de fortalecer o ensino superior e a pesquisa nos países em desenvolvimento, por meio da construção de redes universitárias e de fomento à cooperação. Para tanto, foi instituída, também em 1992, a rede UNITWIN/UNESCO (University Education Twinning and Networking Scheme) visando intensificar a cooperação entre universidades. Atualmente, o programa conta com mais de 700 Cátedras em mais de 20 países, cobrindo os mais diversos campos acadêmicos -- das ciências naturais a questões ambientais e ecológicas, da ciência e tecnologia, ciências sociais e humanas às ciências da educação, cultura e comunicação, e também no campo da paz, da democracia e dos direitos humanos.

A rede UNITWIN tem por objetivo promover troca e compartilhamento de conhecimentos por via da cooperação norte-sul e sul-sul entre universidades e institutos de pesquisa que atuam em parceria com diversas e importantes organizações nãogovernamentais, fundações e instituições do setor público e privado. O UNITWIN cria condições, portanto, para que aqueles que se dedicam ao ensino superior possam somar esforços com a UNESCO para elaboração dos objetivos de uma agenda global, entre eles o fortalecimento do direito à educação. A Faculdade de Direito da USP foi integrada ao programa UNITWIN/UNESCO em 2006.

Neste volume consagrado à celebração dos 120 anos da Faculdade de Direito da Universidade de São Paulo, apresentamos a atual linha de pesquisa da Cátedra UNESCO de Direito à Educação, dedicada à analise das inter-relações entre educação, confiança dos cidadãos nas instituições democráticas e qualidade da democracia, no projeto "Brasil: 25 anos de democracia", desenvolvido em parceria com o Núcleo de 
Políticas Públicas da USP - NUPPS. O projeto consistente na realização de pesquisas e análises críticas acerca dos 25 anos da democracia brasileira (1988/2013), sob três eixos temáticos: (i) instituições democráticas, (ii) relações entre sociedade civil e cultura política e (iii) políticas públicas. Neste último inclui-se, como sub-tema, a análise das interações entre democracia, direito à educação e políticas públicas de educação.

1. Confiança dos cidadãos nas instituições democráticas e qualidade da democracia ${ }^{1}$

No campo da Ciência Política, pesquisas recentes identificaram a confiança do cidadão nas instituições democráticas como um dos componentes indispensáveis para consolidação e aprimoramento das democracias. Reforçando tal evidencia, as mesmas pesquisas demonstram que a desconfiança nas instituições democráticas, tanto quanto o desconhecimento sobre o seu funcionamento, põem em xeque o respeito às leis, enfraquecem as instituições políticas e jurídicas e limitam a sua legitimidade. Concluem, portanto, que a confiança nas instituições democráticas esta relacionada à qualidade da democracia. Em outras palavras: enquanto o regime democrático não for aceito pelas lideranças políticas e pelos cidadãos como a única via possível de exercício do poder estatal, a democracia não se consolida. Mais: para que o regime democrático e suas instituições funcionem bem, seus valores, princípios e instituições devem ser adotados pela maioria dos cidadãos, incondicionalmente, como elemento constitutivo de sua vida política.

As razões da recente problematização da qualidade da democracia pela Ciência Política residem em, pelo menos, três motivos principais. Em primeiro lugar, aprimorar a qualidade da democracia é um dever que decorre dos fundamentos do Estado Constitucional de Direito, até porque a qualidade da democracia é condição da promoção dos direitos fundamentais. Em segundo lugar, a continua melhoria da qualidade da democracia amplia as condições de legitimidade democrática dos Estados, especialmente após períodos de transição de regimes não democráticos, como é o caso do Brasil. Em terceiro lugar, mesmo nos Estados em que a democracia já se encontra consolidada, sempre haverá espaço para a melhoria de sua qualidade.

Até há pouco tempo, não era evidente, para a Ciência Política, que as relações entre democracia, cidadania e confiança nas instituições democráticas fossem relevantes para a teoria da democracia. Embora eleições competitivas e partidos políticos capazes de expressar a diversidade e a pluralidade sociais sejam indispensáveis nas

A reflexão sobre esta temática foi iniciadas na tese de livre-docência por mim defendida na Faculdade de Direito da USP em 2009, sob o título "O Estado democrático de direito e o sentido da exigência de preparo da pessoa para o exercício da cidadania, pela via da educação". 
democracias contemporâneas, não as garantem, não asseguram a sua qualidade, nem esgotam a ordem democrática. A construção de democracias efetivas e de qualidade é problemática e dependente da participação popular. Quanto maiores a desilusão e a insatisfação populares com os regimes democráticos, maior a dificuldade em consolidálos. Também a ineficiência institucional diante de demandas sociais, a fraude, a corrupção e o desrespeito aos direitos fundamentais comprometem a submissão dos cidadãos ao próprio Estado de Direito.

Estas conclusões podem ser comprovadas no caso brasileiro. Entre 1989 ocasião da primeira eleição direta, da qual participaram os cidadãos brasileiros na vigência da Constituição Federal de 1988 - e o pleito de 2010, a valorização da democracia pela população cresceu $21 \%$ (de $43,6 \%$ para $64,8 \%$ ); no mesmo período, diminuiu em $13 \%$ o número de cidadãos incapazes de definir o que é “democracia” (de 38,8\% para 25,5\%). Paralelamente, notou-se o aumento da percepção negativa das instituições estatais por parte da população, em todos os níveis de renda, escolaridade e idade, e em relação a todos os Poderes e partidos políticos, principalmente devido a graves denúncias de corrupção, à malversação de recursos públicos e à falta de qualidade dos serviços públicos (RANIERI, 2009). Em junho de 2013, as manifestações populares que se fizeram notar por todo o país, confirmaram a manutenção daquela tendência negativa. De outra parte, conforme pesquisa realizada por MOISÉS (2010) com o intuito de avaliar a satisfação da população com as instituições políticas, verifica-se que a maioria dos brasileiros considera como válida a opção por uma democracia que prescinda do Congresso Nacional e dos Partidos Políticos.

Embora a democracia brasileira esteja consolidada, com alternância no poder e estabilidade política, tais dados mostram que, se de um lado, a percepção negativa das instituições estatais influi positivamente na disposição dos cidadãos em escolher governantes e representantes, de outro, projeta efeitos negativos na participação política, gerando alienação e desinteresse de parte da maioria da população. Em suma: em vinte anos de regime democrático (período igual ao do regime ditatorial pregresso), tornamonos uma "democracia eleitoral", mas não uma "democracia efetiva", na qual predominem temas como direitos, lei e uma compreensão mais ampla das possibilidades inerentes ao exercício da cidadania no Estado Democrático de Direito. Desconfiança dos cidadãos nas instituições públicas, insatisfação com o desempenho do regime e apoio à democracia convivem, portanto, de forma contraditória.

Há explicações consistentes para esta situação. Malgrado os inegáveis avanços desencadeados pela Constituição Federal de 1988 e a significativa melhoria dos indicadores sociais quando comparados aos períodos anteriores, o País ainda apresenta indicadores sociais ruins. As reformas sociais estão incompletas, havendo ampla margem para o seu aprimoramento em matéria de eficiência e equidade. Permanecem 
iniquidades no campo social e no econômico, resultado do alto nível de pobreza e de baixa escolaridade, dentre outros fatores. Nesse contexto, as demandas pela consolidação da cidadania, identificada como o eixo de articulação das demandas por inclusão e emancipação sociais, próprias das sociedades complexas, desiguais e diferenciadas como a brasileira, superaram as discussões sobre a política e a democratização.

A modéstia dos resultados sociais não faz, de nenhum modo, justiça à intensidade das mudanças que, mesmo sem grandes reformas, alteraram o perfil do Estado Social Brasileiro, inclusive em prol da consolidação da cidadania. A alteração positiva percebida deve-se, fundamentalmente, a quatro condições promovidas pela Constituição: a valorização dos direitos sociais e impulso à sua universalização; a descentralização de competências; os novos parâmetros para alocação de recursos e a redefinição das relações público-privadas no que diz respeito ao financiamento e oferecimento de bens e serviços sociais. É o que se pode observar, particularmente, no campo da educação.

Nos vinte e cinco anos de vigência da atual Constituição, é considerável o progresso dos níveis educacionais da população em geral e dos jovens em particular, tendo-se alcançado, praticamente, a universalização do ensino fundamental. A atuação do Poder Público nesse período assume especial relevância quando consideramos o atraso secular da educação no Brasil, notadamente da educação pública, em comparação a outros países da América Latina, como a Argentina e o Uruguai, que já no início do século XX haviam universalizado a educação fundamental. ${ }^{2}$ Ao que tudo indica, porém, o incremento do acesso à educação básica e a ampliação das matrículas no ensino superior repercutiram em favor de maior qualidade da educação, o que tem repercussões nos processos de superação de diferenças e desigualdades e na participação política relevante (RANIERI, 2009).

É nesse quadro que se insere o projeto "Brasil: 25 anos de democracia", consistente na realização de pesquisas e análises críticas acerca dos 25 anos da democracia brasileira (1988/2013), antes mencionado. Em todo o projeto, a perspectiva de trabalho adotada é a da qualidade da democracia, por via da qual se analisam as relações entre princípios democráticos, procedimentos institucionais, participação política e os resultados do funcionamento das instituições democráticas. Por essa razão, as questões relativas à responsividade (responsiveness) e à responsabilização (accountability) dos governos democráticos, no período pesquisado, têm grande ênfase no projeto.

Embora a proposta de estudo esteja centrada no caso brasileiro, todo o seu desenvolvimento se faz nos marcos da análise comparativa com experiências semelhantes

Cf. FAUSTO, Boris; DEVOTO, Fernando. Brasil e Argentina: um ensaio de historia comparada (18502002). São Paulo: Editora 34, 2004. p. 50 e ss; Ver também MARCílIO, Maria Luiza. História da educação em São Paulo e no Brasil. São Paulo: Imprensa Oficial, 2005; entre outros autores. 
na América Latina e outras regiões do mundo. Com a ampliação do conhecimento do caso brasileiro, o projeto pretende contribuir com a agenda de pesquisa internacional que, depois dos estudos de transição política e consolidação democrática, vem concentrando seus esforços em torno da qualidade das novas democracias. Ao mesmo tempo, esperase que os resultados da pesquisa possam servir de referência crítica para a agenda que envolve o aperfeiçoamento dos modelos de gestão de políticas públicas e de reformas das instituições democráticas.

O projeto é liderado pelo Núcleo de Pesquisa em Políticas Públicas da Universidade de São Paulo - NUPPS e conta com a participação de docentes, pesquisadores e alunos da Universidade de São Paulo - USP, da Universidade de Campinas - UNICAMP, da Pontifícia Universidade Católica de São Paulo - PUC/SP e da Fundação Getúlio Vargas - FGV/SP. Como se pode notar, a Cátedra de Direito à Educação da Faculdade de Direito, ao integrar o projeto, cumpre seu papel de fortalecer o ensino superior e a pesquisa interdisciplinar e de promover a cooperação entre universidades.

2. As interações entre a democracia, o direito à educação e as políticas públicas de educação na pesquisa "Brasil: 25 anos de democracia". A atuação da Cátedra

Desde meados do século passado, a literatura especializada sobre educação é enfática em demonstrar sua relevância para a governança democrática do país e para a formação da cidadania, além de identificá-la como um dos principais instrumentos à disposição do Estado para inverter processos de reprodução de desigualdades sociais. ${ }^{3}$ Educação, nesse sentido, significa acesso a ferramentas cognitivas necessárias para a participação política relevante (Lipset, 1959; Lazarsfeld et al., 1944; Converse, 1972; Dahl, 1967; Almond e Verba, 1968; Key, 1961).

Tal entendimento é expresso no art. 205 da Constituição Brasileira de 1988, que atribui ao processo educacional a finalidade de formação do cidadão, entre outras. $\mathrm{O}$ direito à educação, em consequência, não é ideologicamente neutro; seu conteúdo político nuclear, conforme se depreende da visão global do sistema constitucional, é a difusão e a promoção dos princípios republicano e democrático. A educação, portanto, é uma questão política; uma questão que diz respeito à tomada de decisões coletivas, à legitimação e ao exercício do direito (RANIERI, 2009).

A interação entre democracia, direito à educação e políticas públicas de educação envolve múltiplas questões; seu estudo exige a mobilização de competências teóricas de diferentes áreas do conhecimento (Ciência Política, Ciências Sociais, Educação, Direito etc.) e a análise simultânea de diferentes perspectivas. No âmbito do

Para uma revisão dessa bibliografia, ver, entre outros, McMahon, 2002 e Psacharopoulos, 1988. 
Direito, as pesquisas se concentram na análise da função promocional do Direito na proteção e promoção do direito à educação. $\mathrm{O}$ foco específico na atividade do Supremo Tribunal Federal (STF), do Superior Tribunal de Justiça (STJ) e do Congresso Nacional - 2000/2010.

Nesta vertente específica da pesquisa "Brasil: 25 anos de democracia", os trabalhos vêm sendo desenvolvidos pelos pesquisadores da Cátedra UNESCO de Direito à Educação da Faculdade de Direito da USP, ${ }^{4}$ e tem por objetivos: (i) a sistematização e a análise das decisões proferidas pelo Supremo Tribunal Federal-STF e pelo Superior Tribunal de Justiça-STJ em matéria de educação, de 2000 a 2012; (ii) a sistematização e análise dos projetos de lei apresentados nesse mesmo período ao Congresso Nacional, analisando-se os debates, as condições de aprovação, sanções e vetos.

2.1. A função promocional do Direito na área da educação como justificativa da pesquisa

Em que pese a importância do direto à educação para a consolidação da democracia brasileira, a doutrina sobre as relações Direito e Educação e acerca do papel do Direito na efetivação de políticas públicas de educação é incipiente. Na última década, os debates doutrinários sobre o direito à educação, tanto na área educacional quanto na jurídica, privilegiaram mais a análise de aspectos conjunturais -- nomeadamente das condições de acesso, gestão e financiamento -- que uma abordagem estrutural, na qual os temas da equidade, qualidade e eficiência estivessem informados pela opção política positivada na Constituição.

$\mathrm{Na}$ realidade, a pesquisa sistemática da organização jurídica do ensino brasileiro constitui um campo pouco explorado pelo Direito. Não há, na área jurídica, estudos que permitam avaliar o impacto da legislação na implantação de políticas públicas de educação; além disso, a legislação educacional é mais percebida como ramo do direito administrativo do que área específica, dotada de estruturas e categorias próprias (RANIERI, 2000). Na área educacional, estudos vêm, já há algum tempo, demonstrando que o Direito, na relação educação-sociedade-Estado, foi mais utilizado como técnica de formalização do que como instrumento de racionalidade que poderia contribuir à meta da efetivação da educação (CURY, HORTA E FÁVERO, 1996). Essa situação também

4 Em agosto de 2013, integram o corpo de pesquisadores da Cátedra: Profa. Associada Nina Ranieri (FD/ USP), Prof. Dr. Gustavo Bambini (EACH/USP), Roberto Viecelli e Sara Tironi, alunos de pós-graduação da FD/USP; Elisa Lucena e Rafael Romão bolsistas do NUPPS, Michel Lotaif, aluno de graduação da FD/USP e Yuri César Novais Magalhães Lopes. 
tem possibilitado a preservação, na política e na prática educacionais, das características estatizantes centralizadoras do federalismo brasileiro com prejuízos para a participação mais efetiva da sociedade.

O Direito é assim tomado em sua tradicional formulação liberal (o ordenamento jurídico é uma ordem na qual a validade das normas está baseada em estruturas hierárquicas, de caráter sistêmico, lógico e coerente, capaz de gerar segurança e certeza), sem que garanta, contudo, a funcionalidade de suas normas. Nessa abordagem tampouco é concebido como expressão cultural e função de uma dada sociedade, recepcionando e sancionando os valores materiais que esta lhe oferece e que, incorporados ao direito positivo, atuam como valores jurídicos submetidos à dinâmica própria das regras do Direito.

Resultados de pesquisas anteriores (Ranieri, 2000) mostram que embora na área jurídica, de modo geral, o direito à educação não seja percebido em sua dimensão democrática, a sua efetivação por via jurisprudencial vem apresentando novos campos de afirmação do Estado Democrático de Direito, em benefício dos direitos de cidadania e da participação popular, o que é especialmente importante num país com baixa percepção popular do valor das instituições democráticas e desconhecimento da força normativa da Constituição. Fica, assim, implícita a conclusão de que os mecanismos de tutela judicial dos direitos sociais podem ser extremamente eficazes nas situações em que a política pública se extrai diretamente da Constituição.

\subsection{Objetivos da pesquisa}

A pesquisa enfoca vertentes distintas, porém complementares: o ativismo judicial (a atuação dos Tribunais na fixação de políticas públicas de educação compatíveis com as normas constitucionais de proteção e promoção do direito à educação) e a produção legislativa, nesta última incluída a análise dos projetos de lei não votados no Congresso Nacional. De um lado, portanto, avalia-se o protagonismo dos Tribunais na judicialização das políticas públicas, independentemente da existência de lei; de outro, o protagonismo e a inação do Congresso Nacional, ou a promoção do "engavetamento" de projetos de lei relativos a normas ou políticas públicas de educação. Como esses fenômenos interferem na proteção e promoção do direito à educação? Quais as relações que se estabelecem entre eles? Quais os seus efeitos, individual e conjuntamente considerados? Seria razoável supor que a jurisprudência do STF e do STJ, em relação ao direito à educação, seria materialmente abrangente e não matizada pelos mesmos interesses que atuam em outras instituições democráticas, como o Congresso Nacional, uma vez que a função precípua do órgão é a de guarda da Constituição? 
Sem prejuízo de ter os seus resultados considerados isoladamente, a pesquisa legislativa, na verdade, constitui mais um dado para analise da pesquisa judicial, na medida em que permite identificar a eficácia e a efetividade das políticas públicas formuladas pelos Tribunais Superiores.

A principal inovação da presente pesquisa consiste na análise dos efeitos das decisões judiciais sobre a formulação das políticas públicas, em termos quantitativos e qualitativos. Escolhas orçamentárias, efeito multiplicador, atuação posterior do Legislativo (como ocorreu no julgamento da constitucionalidade de políticas afirmativas educacionais raciais que logo repercutiram na rápida aprovação da Lei n. 12.711/12) etc. Subsidiariamente, será elaborado o "Livro Código Educação / Projeto Brasil - 25 anos de democracia" a partir do banco de dados de decisões judiciais e legislação em matéria educacional criado no NUPPS com o material pesquisado.

\subsubsection{A atividade judicial}

$\mathrm{O}$ direito à educação foi uma temática relativamente marginal na jurisprudência Supremo Tribunal Federal - STF antes da Constituição Federal de 1988, a despeito de também caber ao Tribunal a apreciação de questões relativas à legislação federal. Desde então, a situação se alterou substancialmente. No período compreendido entre 1988 e início de 2013, foram julgados cerca de 4.410 processos, dos quais 4.222 deram entrada a partir do ano $2000 .^{5}$ Desses, até 2009, haviam sido protocolados cerca de 2.250 processos; o restante (cerca de 2.000 processos), deu entrada na Corte em apenas 3 anos, podendo-se observar neste movimento a ampliação da procura de soluções por via da atividade jurisdicional.

Nesse sentido, tem sido particularmente notável a alteração de conteúdo das decisões, em benefício da efetividade do direito à educação, em especial no que concerne à educação básica, com repercussão nas estruturas do Estado Democrático de Direito. O gráfico 1, abaixo, procura demonstrar essa intensa atividade que, apesar de não ser expressiva quantitativamente no conjunto dos casos levados à apreciação do STF, é significativa dessa mudança (RANIERI, 2009).

Cf. Disponível em: <http://www.stf.jus.br>. Acesso em: 10 abr. de 2013. 


\section{Gráfico 1}

Evolução das demandas no STF até 2009

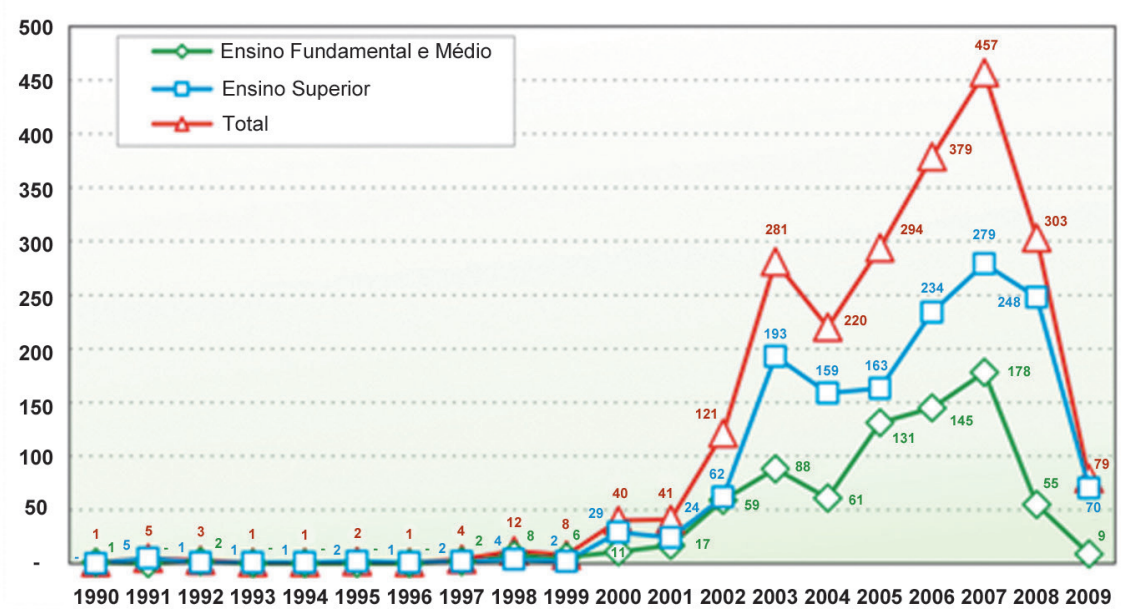

Fonte: Supremo Tribunal Federal. Assessoria de gestão processual, maio de 2009.

No início da década de 1990, por exemplo, prevaleceram as demandas relativas ao controle de mensalidades escolares, em face da disciplina legal de seu reajuste (Lei n. 8.039/90), ao abrigo do art. 173, § 4º da Constituição Federal. Na grande maioria das decisões, o STF pronunciou-se favoravelmente à atuação do Estado, firmando jurisprudência no sentido de salvaguardar o direito à educação de abusos econômicos por parte da iniciativa privada, vedando sanções escolares ao inadimplemento de prestações contratuais pelo estudante. Esse entendimento alterou-se no inicio dos anos 2000; àquela altura e até então, raros foram os casos levados à Corte que, diretamente, demandavam tutela para o exercício individual ou coletivo do direito à educação.

Algumas hipóteses podem explicar o fenômeno do aumento das ações objetivando a efetivação do direito à educação, especialmente no âmbito da educação infantil, em nítida tentativa de concretização sucessiva das metas educacionais: a ampliação da atividade do Ministério Público pela CF/88 (cf. arts. 127 e 129), destacandose a defesa da ordem jurídica, do regime democrático e dos interesses sociais e individuais indisponíveis; a consolidação da ação civil pública para defesa de interesses coletivos; e a criação do Fundo de Desenvolvimento do Ensino Fundamental - FUNDEF, em 1996, que permitiu o equacionamento das questões relativas ao financiamento e expansão da 
educação fundamental por parte dos Estados e Municípios e, por via de consequência, alcançando, em muitos casos, a sua universalização (RANIERI, 2009). ${ }^{6}$

A atuação do STF assume especial relevância quando se considera que, em 1988, parte de suas atribuições foram destinadas ao Superior Tribunal de Justiça - STJ, criado pela Constituição para garantir a interpretação adequada e a unidade do direito federal ordinário, em face das causas julgadas pelos tribunais federais comuns e pelos tribunais estaduais.

Isso significa que os acórdãos do STF analisados a partir do ano 2000 referem-se a questões constitucionais, apenas. Tal análise tem por objetivo precípuo identificar referências de valor relativamente ao direito à educação e, em particular, à educação básica, em benefício de interpretações coerentes e não meramente explicativas do sentido da exigência do art. 205, no que concerne à promoção do direito à educação. $\mathrm{O}$ mesmo se espera em relação ao STJ, sendo que a escolha do ano 2000 como marco inicial de análise dos seus acórdãos deve-se à edição da Lei de Diretrizes e Bases da Educação em 1996 (Lei n. 9.394/96).

A atenção se concentra na educação básica à vista das finalidades desse nível de ensino, sem prejuízo da análise da problemática das ações afirmativas no nível do ensino superior, dadas as suas peculiaridades. Os acórdãos e votos proferidos pela Corte, ademais de revelarem o grau de conhecimento das garantias e direitos previstos na Constituição Federal por parte da sociedade e situarem a problemática da educação no tempo e no espaço, proporcionaram uma ampla visão da evolução dos processos de efetivação do direito à educação, sobretudo pelo exame da adequação do poder discricionário do legislador e do administrador público às políticas públicas veiculadas pela Constituição.

Os acórdãos e votos proferidos, ao revelarem o grau de conhecimento das garantias e direitos previstos na Constituição Federal por parte da sociedade e situarem historicamente a problemática da educação, proporcionam uma ampla visão da evolução dos processos de efetivação do direito à educação, sobretudo pelo exame da adequação do poder discricionário do legislador e do administrador público às políticas públicas veiculadas pela Constituição. Subsidiariamente, permitirão identificar as dificuldades jurídicas de implantação do programa assumido pela Constituição Federal de 1988 nessa área, inclusive no que diz respeito aos documentos internacionais de proteção da pessoa humana incorporados ao sistema jurídico nacional, ainda que não seja este o foco principal da investigação.

\footnotetext{
6 A propósito da projeção de universalização da educação fundamental no Brasil, confira-se o Relatório de Monitoramento Global 2008 sobre Educação da UNESCO. Disponível em: <http://unesdoc.unesco.org/ images/0015/001547/154743e.pdf>.
} 


\subsubsection{Atividade legislativa}

Nesta vertente, a pesquisa procura levantar dados que permitam identificar eventuais conexões entre os projetos de lei relativos á área educacional e as demandas que chegam aos Tribunais superiores. Em caso positivo, de que ordem são tais conexões? É possível correlacionar tais dados, considerando-se que a diferença dos tempos de atuação do Legislativo e do Judiciário podem interferir nessa análise? A apresentação de um projeto na Câmara ou no Senado, contemporaneamente à apreciação das demandas pelo STF, pode indicar a mesma preocupação? Em relação a esse conjunto, seria possível selecionar amostras seguras para análise, considerando-se a inexistência, neste tipo de documento, de qualquer padrão? (variam os partidos, as bases de representação nas diversas regiões do País e, naturalmente, os interesses; não há regularidade nas proposituras, nem por tema, nem por partido, nem por parlamentar, e não há uniformidade nos termos empregados nos projetos).

Como o Congresso Nacional oferece respostas ao protagonismo do STF e STJ na judicialização das políticas educacionais? A edição da Emenda Constitucional n. 53 de 2006, que alterou o inciso VI do art. 208 da Constituição Federal de 1988 para garantir a educação infantil, em creche e pré-escola, às crianças de até 5 (cinco) anos de idade, por exemplo, deu-se após o julgamento, no STF, de diversos recursos extraordinários que, a partir de 2004, objetivaram o acesso universal a este nível de ensino. ${ }^{7}$ Este tipo de encaminhamento do problema não é comum na definição de políticas públicas de educação.

Ainda da perspectiva das respostas do Congresso ao protagonismo dos Tribunais, faz-se necessário cotejar os projetos não aprovados àqueles aprovados, considerando-se: autoria, condições de aprovação, sanção e eventuais vetos. Em relação à autoria, especificamente, quantos projetos, especialmente as que apresentam sucesso de grau mínimo, nasceram do Legislativo? Quantos foram iniciados pelo Executivo, sejam projetos de lei ordinários, complementares ou até mesmo emendas à Constituição?

Adicionalmente, é fundamental analisar a tramitação dos projetos nas Comissões de Educação, da Câmara e do Senado, visando acompanhar o seu andamento e o sucesso da tramitação, que pode estar relacionado ao grau de efetividade dos projetos: fraco (tramitação pautada em Plenário, após votação nas comissões competentes, mas não aprovados pela casa de origem), intermediário (aprovado na Casa de origem, segue para

O Agravo Regimental n. 639.337, cuja decisão foi prolatada em setembro de 2011, trata da obrigatoriedade do Município de São Paulo-SP a matricular crianças em unidades de ensino infantil próximas de sua residência ou do endereço de trabalho de seus responsáveis legais, valendo-se da própria Emenda Constitucional n. 53/2006 para afirmar o direito à educação infantil. Na ocasião, a Segunda Turma do STF decidiu, por unanimidade, que a sentença original que havia determinado a obrigatoriedade com a cominação de multa por descumprimento deveria ser mantida. 
a Casa revisora, mas lá não evoluí) ou forte (aprovado em ambas as Casas e remetido à sanção do Executivo).

Também será possível identificar quantas dessas propostas suscitaram duvidas interpretativas ou questionamentos acerca de sua validade constitucional, sendo encaminhadas para a apreciação do Supremo Tribunal Federal, em sede de controle de constitucionalidade. Tal comparação permitirá evidenciarmos o sucesso legislativo na formulação das políticas públicas educacionais, uma vez que a "boa lei" - isto é, a lei que alcança regularmente os seus objetivos - não é, em tese, revisada pelo Judiciário. A pesquisa permitirá avaliar o grau de interferência dos Poderes da República sobre as políticas públicas educacionais e, em relação a estas, qual (ou quais) tem sido objeto de maior interferência judicial, em sede de controle de constitucionalidade concentrado ou difuso. Todos esses aspectos se relacionam, direta ou indiretamente, à questão da confiança da população no Legislativo.

Frise-se que na área do Direito não há pesquisas empíricas ou reflexões doutrinárias acerca das relações que se procura estabelecer nesta parte da pesquisa, nem acerca do conteúdo de projetos não levados à votação ou não aprovados pelo Congresso Nacional.

3. Resultados parciais

3.1. A pesquisa de jurisprudência no STF e STJ realizada junto aos respectivos sites dos tribunais com as palavras-chaves "direito e ensino" e "direito e educação", apresenta preliminarmente e sem excluir as duplicidades, os resultados resumidos no Quadro 2, conforme identificados e sistematizados pelo pesquisador Roberto Viecelli:

\section{Quadro 2}

STF / STJ - 01/01/ 2000 a 31/12/2010

Acórdãos e repercussões gerais em matéria educacional

\begin{tabular}{|l|l|l|}
\hline \multicolumn{2}{|c|}{ Período pesquisado 01/01/2000 a 31/12/2010 } \\
\hline Tribunal / site & Palavras-chaves & $\begin{array}{l}\text { Número de acórdãos encontrados } \\
\text { no site do tribunal }\end{array}$ \\
\hline STJ (stj.jus.br) & direito e educação & 590 \\
\hline STJ (stj.jus.br) & direito e ensino & 794 \\
\hline STF (stf.jus.br) & direito e educação & 146 \\
\hline STF (stf.jus.br) & direito e ensino & 72 e 4 repercussões gerais \\
\hline & & $\begin{array}{l}\text { Total 1602 acórdãos e } 4 \\
\text { repercussões gerais }\end{array}$ \\
\hline
\end{tabular}


No atual estágio, avalia VIECELLI, a pesquisa permitiu observar o protagonismo do STJ no julgamento das ações que envolvem o direito à educação sob a Lei de Diretrizes e Bases de 1996 (LDB), lei federal cuja interpretação lhe incumbe uniformizar. No STF, em relação à mesma matéria, apenas 38 demandas foram julgadas; destas, $47,3 \%$ (18) são ações originárias de controle abstrato de constitucionalidade, propostas diretamente perante o STF, em Brasília.

Observou-se, ainda, que o acesso ao STJ se dá majoritariamente pela via recursal; são poucas as demandas originárias (como mandados de segurança contra o Ministro da Educação, por exemplo). O Quadro 3, abaixo, retrata a correlação entre os anos de vigência da LDB e a quantidade de demandas que chegam ao STJ:

\section{Quadro 3}

Variação temporal do número de acórdãos do STJ sobre a LDB1996

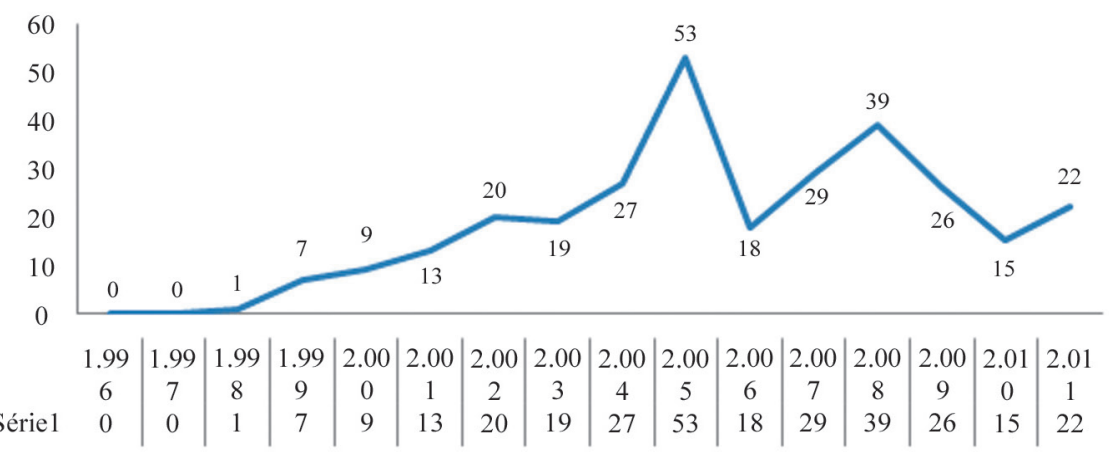


3.2. Ainda de acordo com VIECELLI, a análise quantitativa dos julgados indicou desigualdades regionais em relação ao acesso ao Judiciário, destacando-se as regiões Sul e Sudeste assim como o Distrito Federal como locais de maior número de ações interpostas, como se nota no Quadro 4:

\section{Quadro 4}

\section{Percentual de demandas no STJ por Região de origem}

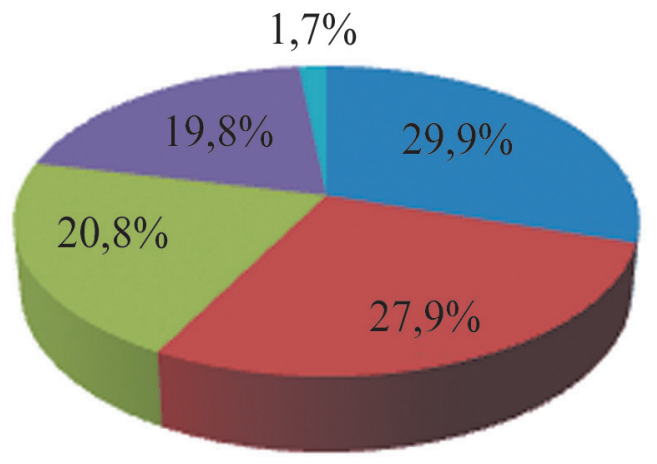

$\square \mathrm{Sul}$

口 Sudeste

Centro-Oeste

nordeste

Norte

De modo geral, são demandantes junto ao STJ: Ministério Público, alunos, universidades, escolas de ensino médio federais; instituições privadas de ensino; conselhos profissionais; a União, os Estados e os Municípios. O Ministério Público tem atuado, principalmente, nas ações relativas ao acesso a creches. Os alunos são os principais demandantes, sendo inexpressiva atuação dos entes federativos (ver Quadro 5). A maioria dos recursos interpostos por alunos refere-se ao reconhecimento de diplomas relacionados à área da saúde obtidos no estrangeiro. 


\section{Quadro 5}

\section{Atores que mais litigam sobre matérias da LDB-1996 perante o STJ}

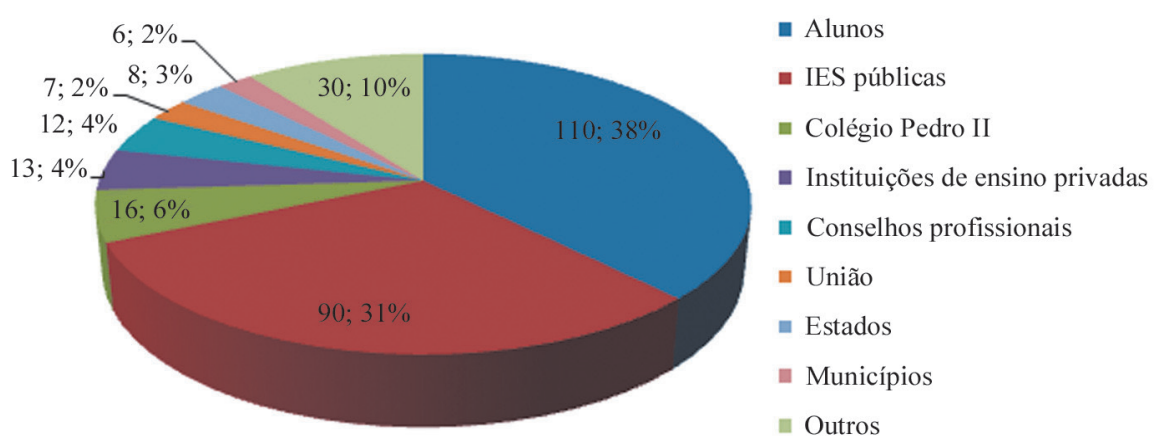

Quanto ao número de provimentos, no STJ verificou-se que 107 de 286 (ou seja, 37,41\%) demandas foram providas (excluídos os conflitos de competência, por consistirem precipuamente em questões suscitadas entre juízes). O percentual de provimento é relativamente alto, considerando-se a natureza recursal das demandas que chegam à Corte.

3.3. Quanto à matéria, os processos judiciais relativos a educação básica que chegam aos Tribunais superiores versam, fundamentalmente, sobre condições de acesso ao ensino fundamental e pré-escola, creches aí incluídas. De resto, os processos tendem a pedir a solução de pleitos individuais (revalidação de diplomas, aproveitamento de estudos, transferência de servidor público e matrícula obrigatória no local de residência, sanções etc.). No geral, são poucas as demandas de alcance social mais amplo, como ocorreu em relação ao paradigmático caso das vagas em creches. Não há, por exemplo, demandas relativas à melhoria da qualidade de ensino, temática constante e predominante nas manifestações populares de junho de 2013 ocorridas em grande parte do País

No que diz respeito às demandas por acesso à educação básica, o número de processos que chegam ao STJ tende a diminuir. Em primeiro lugar, devido à jurisprudência que vem se pacificando em relação a este tema; em segundo lugar, em razão da edição 
de normas federais que asseguram novos direitos (das quais o acesso a creches e a constitucionalidade das cotas raciais são exemplos); em terceiro lugar, devido às novas normas de processo civil (o projeto do Novo Código de Processo Civil, que visa banir os recursos de decisões interlocutórias das quais caberiam apenas o mandado de segurança; o instituto do prequestionamento, da inadmissão do recurso quando contrariar súmula ou jurisprudência dominante etc.).

3.4. Na pesquisa relativa aos projetos de lei aprovados e não aprovados pelo Congresso Nacional, conduzida pelo Prof. Gustavo Bambini e pelos pesquisadores Sara Tironi e Michel Lotaif, ainda em andamento, foram identificados 164 projeto de lei ordinária relativos à educação básica, exclusivamente, e 926 que tratam de ensino superior e técnico. Ainda restam 1363, que demandam a análise para verificação de sua pertinência com o projeto. Isso é o que está sendo feito no momento. $\mathrm{O}$ passo seguinte será pesquisar incluir os projetos de lei complementar, de emenda constitucional, de lei de conversão e medidas provisórias nas amostras de pesquisa

4. Conclusões parciais

4.1. Como as leis não são neutras, uma vez acionados, os tribunais acabam por exercer uma influência política considerável, como já demonstrado na doutrina (TAYLOR, 2008, p. 5)

4.2. Da mesma forma, como já apontado por BAIRD e HURWITZ (2002, p. 1), decisões jurisprudenciais influenciam o Congresso. Exemplos:

4.2.1. Acesso a creches e ampliação da educação básica obrigatória: EC 59/2009 e Lei n. $12.796 / 2013$

4.2.2. Ações afirmativas - decisões do STF relativas à constitucionalidade das cotas raciais (ADPF n. 186/DF) e das cotas para egressos de escolas públicas (RE n. 597.285/RS) para o ingresso em universidade pública. Os efeitos destas decisões se mostraram nítidos na acelerada tramitação e aprovação do Projeto de Lei n. 180 de 2008, que originou a Lei n. 12.711/12, que dispõe sobre a distribuição das vagas nas instituições de ensino superior federais, ${ }^{8}$ regulamentada, dois meses após, pelo

Em síntese, o que a lei determina é a reserva, progressivamente no prazo de 4 anos, de no mínimo $50 \%$ das vagas aos egressos de escolas públicas e aos autodeclarados pretos, pardos e indígenas, na proporção populacional desses grupos no respectivo Estado-membro. (arts. $1^{\circ}$ e $3^{\circ}$ ). 
Decreto n. 7.824, de 11 de outubro de 2012

4.3. O Judiciário amplia o leque de atores influentes nesse processo (Ministério Público, Defensorias), haja vista que incrementa a venue-seeking, conceito que sugere que os atores procuram as vias, instâncias institucionais, que mais lhes convêm administrativa, legislativa ou judiciária (TAYLOR, 2007)

4.4. O Judiciário é uma via cada vez mais acessível à população para demanda de proteção e garantia do direito à educação

4.5. O aumento do número de demandas junto ao Judiciário é, ao mesmo tempo, indicador do déficit legislativo e da ineficácia ou ineficiência das leis aprovadas. Diante do grande número de projetos legislativos não votados em matéria educacional, adota-se a segunda premissa como hipótese preliminar

4.6. Do ponto de vista da legislação, a ineficácia das leis transmite a ideia generalizada de ausência de orientação e de baixas expectativas normativas. Em outras palavras, o texto legal não é capaz de dirigir normativamente a conduta de seus destinatários (responsáveis pela efetivação das políticas públicas).

\section{Conclusão}

A chamada "judicialização da política", baseada na ideia de controle de políticas públicas evidencia, em si, um problema. Privilegiando o acesso em detrimento da qualidade do ensino, o Judiciário acaba por se restringir a solucionar pendências setorizadas e provocar a fragmentação das políticas públicas, que deveriam se dirigir no sentido de uma política geral de desenvolvimento. Desse problema também padece o Legislativo e o Executivo: o Relatório do Banco Interamericano de Desenvolvimento/ David Rockefeller Center for Latin America Studies-Harvard University constatou que "a formulação de políticas educacionais na América Latina é desproporcionalmente tendenciosa em favor de políticas com ênfase em expansão e acesso, em vez de qualidade e eficiência." (BID/Harvard, 2007, p. 224).

A efetivação do direito à educação por via jurisprudencial revela novos campos de afirmação do Estado Democrático de Direito, em benefício dos direitos de cidadania e da participação popular, o que é especialmente importante num País com baixa percepção popular do valor das instituições democráticas e desconhecimento da força normativa da Constituição. Fica, assim, implícita a conclusão de que os mecanismos de tutela judicial dos direitos sociais podem ser extremamente eficazes nas situações em que a política pública se extrai diretamente da Constituição. 
Esta conclusão sugere, por decorrência lógica, que a definição constitucional de objetivos, metas e prioridades, combinada com a precisa discriminação de competências, encargos e rendas aos entes da Federação e com a vinculação de recursos financeiros, permite a sua realização a médio prazo. O mais importante, porém, é que, garantidas judicialmente, as normas de proteção dos direitos sociais passam, de programáticas, a ser normativas. Isso significa que, sem o filtro de eficácia representado pelo legislador, suas disposições consubstanciam obrigações diretamente acessíveis e exigíveis pelo particular, de modo independente, em suas relações privadas ou face ao Estado.

Dessa perspectiva, se por um lado a atuação do Judiciário ainda exige o enfrentamento de questões práticas, como por exemplo, a da compatibilização dos seus tempos de manifestação com a urgência das demandas, de outro aponta na direção de uma hermenêutica constitucional com alto grau de criatividade na garantia de direitos fundamentais, contra o arbítrio e a omissão estatais, seja do Executivo seja do Legislativo.

A atuação positiva do Judiciário apenas reverterá em políticas públicas concretas e consequente promoção do direito à educação caso os demais Poderes executem as decisões judiciais, generalizando o conteúdo dos provimentos judiciais garantidores de direitos sociais. Por isso, não se trata apenas da existência de legislação apropriada ou de decisões favoráveis à efetivação de políticas públicas em educação, mas, sobretudo da capacidade das instituições estatais em assegurar a efetividade do sistema legal democrático.

São Paulo, junho de 2013.

\section{Referências}

ALMOND, G.; VERBA, S. The civic culture: political attitudes and democracy in five nations. Princeton: Princeton University Press, 1968.

ASSIS, Luiz Gustavo Bambini de. Processo Legislativo e orçamento público: função de controle do Parlamento. 1. ed. São Paulo: Saraiva, 2012. v. 1. 297 p.

BID (Banco Interamericano de Desenvolvimento); Harvard University - David Rockefeller Center for Latin America Studies. A política das políticas públicas: progresso econômico e social na América Latina: relatório 2006. Rio de Janeiro: Elsevier: Washington, DC: BID, 2007.

BAURIES, Scott. Is There an Elephant in the Room?: Judicial Review of Education Adequacy and the Separation of Powers in State Constitutions". Alabama Law Review, v. 61:4, p. 701-772, 2010. Disponível em: <http://uknowledge.uky.edu/law_facpub/31/>.

BOBBIO, Norberto. A era dos direitos. São Paulo: Campus, 1992. 
CONVERSE, P. E. The human meaning of social change. New York: Russel Sage Foundation, 1972.

CURY, C. R. J.; HORTA, J. S. B.; FÁVERO, O. A relação educação-sociedade-estado pela mediação jurídico constitucional. In: FÁVERO, O. (Org.). A educação nas constituições brasileiras: 18231988. Campinas: Ed. Autores Associados, 1996. p. 05-30.

DAHL, R A. Pluralist democracy in the United States. Chicago: Rand McNally, 1967.

DURHAM, E. R. Democracia e educação: O ensino médio e o ENEM. Blog Qualidade de Democracia, São Paulo. Disponível em: <http:/qualidadedademocracia.com.br/democracia-eeducacao-o-ensino-medio-e-o-enem/>. Acesso em: 15 out. 2012.

FAUSTO, Boris; DEVOTO, Fernando. Brasil e Argentina: um ensaio de historia comparada (18502002). São Paulo: Editora 34, 2004. p. 50 e ss..

KEY, V. O. Public opinion and American democracy. New York: Alfred A. Knopf, 1961.

LAZARSFELD, P. F.; BERELSON, B.; GAUDET, H. The people's choice. New York: Columbia University Press, 1955.

LIPSET, S. M. (1959). Some social requirements of democracy: economic development and political legitimacy. American Political Science Review, v. 53, n. 1, p. 69-105, 1959.

NEVES, Marcelo. A constitucionalização simbólica. 2. ed. São Paulo: Martins Fontes: 2007.

MCMAHON, W. W. Education and development: measuring the social benefits. Oxford: Oxford University Press, 2002.

MARCILIO, Maria Luiza Marcílio. História da educação em São Paulo e no Brasil. São Paulo: Imprensa Oficial, 2005.

MOISÉS, José Álvaro. Cultura política, instituições e democracia: lições da experiência brasileira. Revista Brasileira de Ciências Sociais, São Paulo, v. 23 n. 66, fev. 2008. Disponível em: <http:// dx.doi.org/10.1590/S0102-69092008000100002>.

MOISÉS, José Álvaro. Democracia e confiança: por que os cidadãos desconfiam das instituições públicas? São Paulo: Edusp, 2010.

PSACHAROPOULOS, G. Education and development. A Review. The World Bank Research Observer, v. 3, n. 1, p. 100-116, 1988.

RANIERI, Nina Beatriz Stocco. Educação Superior, Direito e Estado na Lei de Diretrizes e Bases (Lei n. 9.394/96). São Paulo: Edusp, Fapesp, 2000.

O Estado democrático de direito e o sentido da exigência de preparo da pessoa para o exercício da cidadania, pela via da educação. 2009. Tese (Livre docência), Faculdade de Direito da Universidade de São Paulo, São Paulo. 
. Os Estados e o Direito a Educação na Constituição de 1988 - Comentários acerca da jurisprudência do Supremo Tribunal Federal. In: RANIERI, Nina Beatriz Stocco. (Coord.); RIGHETTI, Sabine (Org.). Direito à educação: aspectos constitucionais. São Paulo: Edusp, 2009. 183.

. O Supremo Tribunal Federal e o direito internacional à educação: a promoção indireta dos princípios e normas internacionais. In: AMARAL JÚNIOR, Alberto do; JUBILUT, Liliana Lyra (Orgs). O STF e o direito internacional dos direitos humanos. São Paulo: Quartier Latin, 2009.

RUSSO, Charles J. Reuter's: the law of public education. 7. ed. New York: Thomson Reuters Foundation Press, 2009.

SADEK, Maria Tereza. Judiciário: mudanças e reformas. Estudos Avançados, São Paulo, v. 18, n. 51, p. 79-101, mai./ago., 2004. Disponível em: <http://www.scielo.br/pdf/ea/v18n51/a05v1851. pdf $>$.

. (2011). "Judiciário e arena pública: um olhar a partir da ciência política”. In: GRINOVER, Ada Pellegrini; WATANABE, Kazuo (Coords.). O controle jurisdicional de Políticas Públicas. São Paulo: Método, 2011.

SALLES, Carlos Alberto. Duas faces da proteção judicial dos direitos sociais no Brasil. In: SALLES, Carlos Alberto de. (org.) As grandes transformações do Processo Civil Brasileiro: estudos em homenagem ao Professor Kazuo Watanabe. São Paulo: Quartier Latin, 2009. p. 792.

- Coisa julgada e extensão dos efeitos da sentença em matéria de direitos sociais constitucionais. In: GOZZOLI, Maria Clara; CIANCI, Mirna; CALMON, Petrônio; QUARTIERI, Rita. (Coord.). Em defesa de um novo sistema de processos coletivos: estudos em homenagem a Ada Pellegrini Grinover. São Paulo: Saraiva, 2010.

TAYLOR, Matthew M. Judging policy: courts and policy reform in democratic Brazil. Standford: Standford University Press, 2008.

O judiciário e as políticas públicas no Brasil. Dados, Rio de Janeiro, v. 50, n. 2,

2007. Disponível em: <http://www.scielo.br/scielo.php?script=sci_arttext\&pid=S0011$52582007000200001 \& \operatorname{lng}=\mathrm{en} \& \mathrm{nrm}=\mathrm{iso}>$.

TOMASEVSKI, Katarina. Removing obstacles in the way of the right to education. In: Right to Education Primers. Gothenburg: Novum Grafiska, 2001. n. 1.

. Free and compulsory education for all children: The gap between promise and performance. In: Right to Education Primers. Gothenburg: Novum Grafiska, 2001. n. 2.

- Human rights obligations: making education available, accessible, acceptable and adaptable. In: Right to education primers. Gothenburg: Novum Grafiska, 2001. n. 3.

. Human rights in education as prerequisite for human rights education. In: Right to education primers. Gothenburg: Novum Grafiska, 2001. n. 3. 
Education denied - costs and remedies. London. New York: Zed Books, 2003.

VIECELLI, R. D. C. A efetividade do direito à educação e a justiciabilidade das políticas públicas na jurisprudência do STF (1988-2011)142. Revista de Direito Educacional, a. 3, v. 5, p. 211- 243, jan./jun. 2012.

VIECELLI, R. D. C. O ciclo da Judicialização das Políticas Públicas: A Lei de Diretrizes e Bases Da Educação Nacional de 1996 e os efeitos indiretos externos das decisões do STJ E STF 143. Revista de Direito Educacional, a. 3, v. 6, p. 261-283, jul./dez. 2012. 